\title{
DESEMPENHO PRODUTIVO DE CULTIVARES DE MORANGUEIRO
}

\section{AGRONOMIC PERFORMANCE OF STRAWBERRY CULTIVARS}

\author{
Roberto Pedroso de OLIVEIRA ${ }^{1}$ \\ Walkyria Bueno SCIVITTARO ${ }^{2}$
}

\begin{abstract}
RESUMO
Avaliou-se o desempenho produtivo da cultivar Ventana de morangueiro, comparando-o com o das cultivares Aromas e Camarosa. O experimento foi realizado em Pelotas, no Rio Grande do Sul, utilizando-se sistema de produção sob túnel e mudas importadas do Chile. O transplantio das mudas foi realizado em junho de 2007, no espaçamento de $35 \mathrm{~cm}$ entre linhas e entre plantas. O delineamento experimental foi de blocos casualizados com parcelas subdivididas no tempo $e$ quatro repetições. As unidades experimentais foram constituídas por 20 plantas. Semanalmente, de agosto a dezembro, foram analisados a massa fresca e o número de frutas produzidas. As cultivares Aromas e Camarosa apresentaram maior regularidade de produção e as cultivares Camarosa e Ventana maior precocidade. As cultivares Aromas, Camarosa e Ventana foram semelhantes quanto ao desempenho produtivo, com produção média acumulada de 709,740 e $692 \mathrm{~g}$ de frutas comerciais por planta. A massa média das frutas da cultivar Ventana é elevada $(>24,1 \mathrm{~g})$ até a décima segunda semana de produção, embora não diferiu estatisticamente para esta variável com a cultivar Ventana, da $5^{\mathrm{a}}$ a $8^{\mathrm{a}}$ semana.
\end{abstract}

Palavras-chave: Fragaria x ananassa; produtividade; massa fresca das frutas; 'Aromas'; 'Camarosa'; 'Ventana'.

\section{ABSTRACT}

The aim of this work was to compare the agronomic performance of Ventana, Aromas and Camarosa strawberries cultivars. The experiment was carried out in Pelotas, Rio Grande do Sul state, using tunnel system and plants imported from Chile. In June 2007, the genetic material were transplanted at the distance of $35 \mathrm{~cm}$ between lines and between plants. The experimental design was a randomized complete block with split plot and four replications. The experimental units were composed by 20 plants. Weekly, from August to December, the variables fruit fresh weight and number of fruits produced in each experimental unit were studied. Aromas and Camarosa cultivars showed greater regularity of the fruit production, and Camarosa and Ventana cultivars greater precocity. Aromas, Camarosa and Ventana cultivars were similar about agronomic performance, with an average production of 709,740 and $692 \mathrm{~g}$ of commercial fruits per plant. The average mass of de fruit of the cultivar Ventana is high $(>24,1 \mathrm{~g})$ until the twelfth week of production, although not statistically different for this variable with the cultivar Ventana, the $5^{\text {th }}$ to 8 weeks.

Key-words: Fragaria x ananassa; productivity; mass of fruit fresh; 'Aromas'; 'Camarosa'; 'Ventana'. 
OLIVEIRA, R.P.; SCIVITTARO, W.B. Desempenho produtivo de...

\section{INTRODUÇÃO}

O morangueiro (Fragaria $\mathrm{x}$ ananassa Duch.) pertence à família das Rosaceas, sendo um híbrido resultante das espécies americanas $F$. Chiloensis, F. Virginiana e F. Ovalis, e da européia Fragaria vesca (Ronque, 1998). No Brasil, a cultura encontra-se difundida em regiões de clima temperado e sub-tropical, onde se produz morango para consumo in natura e para a industrialização, destacando-se pela alta rentabilidade por área e demanda intensa de mão-de-obra (Santos, 2003).

A produção mundial de morango é de 3,1 milhões de toneladas por ano e a brasileira de 40 mil toneladas, obtida em uma área estimada de 3.500 ha, com destaque para os Estados de Minas Gerais $(41,4 \%)$, Rio Grande do Sul $(25,6 \%)$ e São Paulo (15,4\%) (AGRIANUAL, 2008). As principais cultivares utilizadas no Brasil provém dos Estados Unidos, destacando-se a Aromas, Camarosa, e Oso Grande, da Espanha (cultivar Milsei-Tudla) e do programa de melhoramento genético da Embrapa Clima Temperado (cultivares Bürkley, Santa Clara e Vila Nova) (Oliveira et al., 2005).

No Sul do Brasil, as cultivares Camarosa e Aromas são, respectivamente, as cultivares de dia curto e de dia neutro mais utilizadas. A cultivar $\mathrm{Ca}-$ marosa foi obtida na Universidade da Califórnia, em 1993 , tendo plantas vigorosas, com folhas grandes de coloração verde-escura. O ciclo é precoce, com alta capacidade de produção, apresentando frutas grandes, uniformes, de coloração vermelha-escura, polpa firme e sabor sub-ácido. Indicada tanto para consumo in natura quanto para industrialização. A cultivar Aromas também foi desenvolvida na Universidade da Califórnia, porém em 1997, sendo citada como muito produtiva, de hábito de crescimento ereto; frutas grandes, com coloração vermelhaintensa, sabor agradável e qualidade excelente para consumo in natura e industrialização (Oliveira et al., 2008).

Em razão da diversidade edafoclimática existente no País, o pequeno número de cultivares disponível tem sido um dos principais obstáculos ao desenvolvimento da cultura do morangueiro, sendo importante incentivar os programas nacionais de melhoramento genético e de introdução de cultivares geradas em outros países. Nesse contexto, a cv. Ventana é uma das novidades do mercado brasileiro para a maioria dos produtores de morango, tendo sido obtida pela Universidade da Califórnia, em 2001, e introduzida no Brasil em 2005. Atualmente, segundo os viveiristas, a área plantada com essa cultivar não chega a 20 ha no País, principalmente devido a pouca informação tecnológica. Trata-se de uma cultivar de dias curtos, que apresenta plantas vigorosas, grandes e bastante eretas; com alta capacidade de produção; frutas de coloração vermelha-brilhante, grandes, moderadamente firmes, ótimo formato e bom sabor, com aptidão para consumo in natura e industrialização (Larson \& Shaw, 2009).

O objetivo desse trabalho foi avaliar o de- sempenho produtivo da cultivar Ventana de morangueiro, comparando-o com o das cultivares Aromas e Camarosa, nas condições climáticas do Sul do Brasil.

\section{MATERIAL E MÉTODOS}

O experimento foi conduzido em Pelotas, Rio Grande do Sul, Brasil (latitude $31^{\circ} 46^{\prime} 19^{\prime \prime} \mathrm{S}$, longitude $52^{\circ} 20^{\prime} 33^{\prime \prime}$ e altitude de $57 \mathrm{~m}$ ), utilizandose sistema de produção sob túneis. Estes apresentavam $0,5 \mathrm{~m}$ de altura na parte central, sendo sustentados por arcos de arame galvanizado número 6 e cobertos com filme de polietileno transparente aditivado, com 100 micras de espessura.

O ensaio foi realizado em canteiros com $1,05 \mathrm{~m}$ de largura e $0,15 \mathrm{~m}$ de altura, espaçados entre si em $0,8 \mathrm{~m}$, construídos com solo previamente corrigido quanto à acidez. Utilizou-se um sistema de irrigação por gotejamento, sendo as mangueiras distribuídas nos canteiros anteriormente a seu revestimento com filme de polietileno preto, com 30 micras de espessura. As mudas de morangueiro foram transplantadas em $1^{\circ}$ de junho de 2007, sendo dispostas três linhas por canteiro. O espaçamento entre linhas e entre plantas foi de $0,35 \mathrm{~m}$.

Avaliaram-se três cultivares de morangueiro (Aromas, Camarosa e Ventana), usando mudas resfriadas, procedentes do Chile. Antes do transplantio, todas as folhas foram removidas, sendo feita a poda das raízes. Utilizou-se um delineamento experimental de blocos ao acaso com parcelas subdivididas no tempo e quatro repetições, sendo as unidades experimentais constituídas por 20 plantas.

Semanalmente, determinaram-se a massa fresca e o número de frutas produzidas por unidade experimental. Somente foram colhidas as frutas totalmente vermelhas. A massa média das frutas foi calculada pela razão entre essas duas variáveis. Determinou-se, ainda, a produção acumulada de frutas ao longo do período de colheita. Para o experimento, foram descartadas frutas com defeitos de formato, podres ou com massa inferior a $3 \mathrm{~g}$. O período de colheita de frutas estendeu-se de agosto a dezembro de 2007, totalizando 20 semanas de avaliações. Após esse período, as avaliações foram suspensas, em razão da redução na qualidade e quantidade das frutas produzidas, inviabilizando a manutenção do cultivo. Porém, para a análise estatística, agruparam-se os dados a cada quatro semanas, perfazendo cinco períodos de avaliação. Os dados, transformados para log $(x+1)$, foram submetidos à análise de variância, comparando-se as médias do fator cultivar pelo teste de Tukey $(p \leq 0,05)$ e do fator período de avaliação, por análise de regressão polinomial.

Durante o experimento, o controle das plantas daninhas, a remoção de folhas secas ou com sintomas de doenças, de estolões e de frutas estragadas ou com defeitos foi feita manualmente. A irrigação das plantas foi realizada de acordo com a necessidade hídrica. Semanalmente estas foram 
OLIVEIRA, R.P.; SCIVITTARO, W.B. Desempenho produtivo de...

fertirrigadas, com aplicações alternadas dos fertilizantes $\mathrm{KSC}^{\circledR}{ }^{\circledR}, \mathrm{KSC}^{\circledR}$ e nitrato de cálcio (500 g por 1000 plantas). O tratamento fitossanitário incluiu duas aplicações de Rovral $\circledast$ (ipridiona), a $150 \mathrm{~mL}$ por $100 \mathrm{~L}$, em agosto e outubro, e uma de Amistar® (azoxistrobina), a $128 \mathrm{~g}$ por ha, em setembro, para o controle de antracnose e micosfarela; uma aplicação de Vertimec $®$ (abamectina), a $75 \mathrm{~mL}$ por $100 \mathrm{~L}$, em novembro, para o controle dos ácaros branco e rajado; e a utilização de iscas (frutos esmagados com malation), em novembro e dezembro, para controle da broca dos frutos.

O manejo dos túneis plásticos consistiu em sua abertura do lado oposto aos ventos predominantes, até a altura de $0,4 \mathrm{~m}$ nas manhãs mais quentes, sendo fechados no final de tarde e antes da ocorrência de chuvas e/ou neblinas.

\section{RESULTADOS E DISCUSSÃO}

Para todas as variáveis medidas, verificouse significância da interação cultivar $x$ período de avaliação (Tabelas 1 a 3 ). Apenas no primeiro período de avaliação ( $1^{\mathrm{a}}$ a $4^{\mathrm{a}}$ semanas), não houve diferença entre as cultivares quanto à produção de frutas de morangueiro. Nos períodos subsequentes, houve alternância quanto à cultivar mais produtiva. A cultivar Camarosa apresentou desempenho superior entre a $5^{\mathrm{a}}$ e $8^{\mathrm{a}}$ semanas de colheita; no período seguinte ( $9^{\mathrm{a}}$ a $12^{\mathrm{a}}$ semanas), a 'Ventana' foi mais produtiva. Nos dois últimos períodos $\left(13^{\mathrm{a}}\right.$ a $16^{\mathrm{a}} \mathrm{se}-$ manas e $17^{a}$ a $20^{a}$ semanas), maior produtividade foi determinada para a 'Aromas', sendo que, neste último, seu desempenho foi equiparado pela 'Camarosa' (Tabela 1). Os padrões de produção das cultivares Camarosa e Ventana ao longo do período de colheita foram semelhantes, com maior precocidade de produção relativamente à 'Aromas', que inicialmente foi menos produtiva, superando as

TABELA 1 - Produtividade de frutas comerciais de morangueiro em função da cultivar e do período de avaliação.

\begin{tabular}{llcccc}
\hline \multirow{2}{*}{ Cultivar } & \multicolumn{5}{c}{ Período de avaliação ${ }^{1}$, semanas } \\
\cline { 2 - 5 } & \multicolumn{1}{c}{ 1 a 4} & 5 a 8 & 9 a 12 & 13 a 16 & 17 a 20 \\
\hline & & & & & \\
& & & & & \\
Aromas & $38,7^{\text {ns }}(5,5)^{2}$ & $68,6 b(9,7)$ & $226,1 b(31,9)$ & $255,2 a(36,0)$ & $120,1 \mathrm{a}(16,9)$ \\
Camarosa & $39,7(5,4)$ & $177,1 \mathrm{a}(23,9)$ & $211,3 \mathrm{~b}(28,5)$ & $218,9 \mathrm{~b}(29,6)$ & $93,3 \mathrm{ab}(12,6)$ \\
Ventana & $59,1(8,5)$ & $88,4 \mathrm{~b}(12,8)$ & $283,3 \mathrm{a}(41,0)$ & $190,3 \mathrm{~b}(27,5)$ & $70,4 \mathrm{~b}(10,2)$ \\
\hline
\end{tabular}

CV(cultivar) $=7,5 \%$

$\mathrm{CV}($ período de avaliação $)=12,7 \%$

${ }^{1}$ Período de avaliação a partir do início da colheita em agosto. ${ }^{2}$ Valores entre parênteses correspondem ao percentuais da produção no período de avaliação.

Médias seguidas de mesma letra nas colunas não diferem significativamente entre si pelo teste de Tukey $(p<0,05)$.

Ainda com relação ao desempenho produtivo das cultivares de morangueiro, relata-se a ocorrência de variações na regularidade de produção. A 'Ventana' caracterizou-se por apresentar floradas intensas e periódicas ao longo de todo o período de produção, comportamento esse evidenciado a partir das avaliações semanais (dados parciais não apresentados). Já as cultivares Camarosa e Aromas apresentaram maior regularidade de produção, decorrente de florações mais frequentes e uniformes dentro de cada período de avaliação, o que é uma característica muito valorizada pelos produtores, por garantir estabilidade de abastecimento aos mercados demandantes (Rebelo \& Balardin, 1997).

Para as três cultivares de morangueiro, os dados de produção acumulada de frutas ao longo do período de colheita ajustaram-se a modelos lineares crescentes (Figura 2). Ao final do período de avaliação, não se determinou diferenças entre as cultivares quanto à produção acumulada de frutas, a qual totalizou $740 \mathrm{~g}$ de frutas comerciais por planta para 'Camarosa', $709 \mathrm{~g}$ para 'Aromas' e $692 \mathrm{~g}$ para 'Ventana' (Tabela 2). Esses resultados demonstram que as três cultivares obtidas pelo programa de melhoramento genético da Universidade da Califórnia são equivalentes quanto ao desempenho produtivo nas condições climáticas da região de cultivo, caracterizadas por temperaturas médias de 11,$9 ; 16,6 ; 18,0 ; 17,9$ e $21,9^{\circ} \mathrm{C}$, respectivamente, do primeiro ao quinto períodos de colheita. A produtividade obtida foi satisfatória, tendo sido superior à média brasileira, próxima aos $700 \mathrm{~g}$ por planta utilizado como referencial de produtividade pelo AGRIANUAL (2008), considerando frutos a partir de $3 \mathrm{~g}$. Entretanto, bastante superior aos $300 \mathrm{~g}$ por planta considerado na prática como patamar de viabilidade econômica para a cultura (Rebelo \& Balardin, 1997). Na Itália, também sob condições de ambiente protegido, D'Anna \& Prinzivalli (2002) obtiveram índices de produtividade bastante inferiores para as cultivares Camarosa e Aromas, respectivamente de $428 \mathrm{~g}$ e de $382 \mathrm{~g}$ de frutas comerciais por planta, não tendo sido constatado o mesmo nível de adaptação dessas cultivares às condições italianas. Por 
OLIVEIRA, R.P.; SCIVITTARO, W.B. Desempenho produtivo de...

outro lado, Leis et al. (2002) obtiveram produções de frutas por planta das cvs. Aromas e Camarosa semelhantes às do presente trabalho. Como a produção e a qualidade das frutas de morangueiro são influenciadas pela interação entre o fotoperíodo e a temperatura (Durner et al., 1987), as cultivares devem ser avaliadas regionalmente quanto ao desempenho agronômico (Santos, 2003).

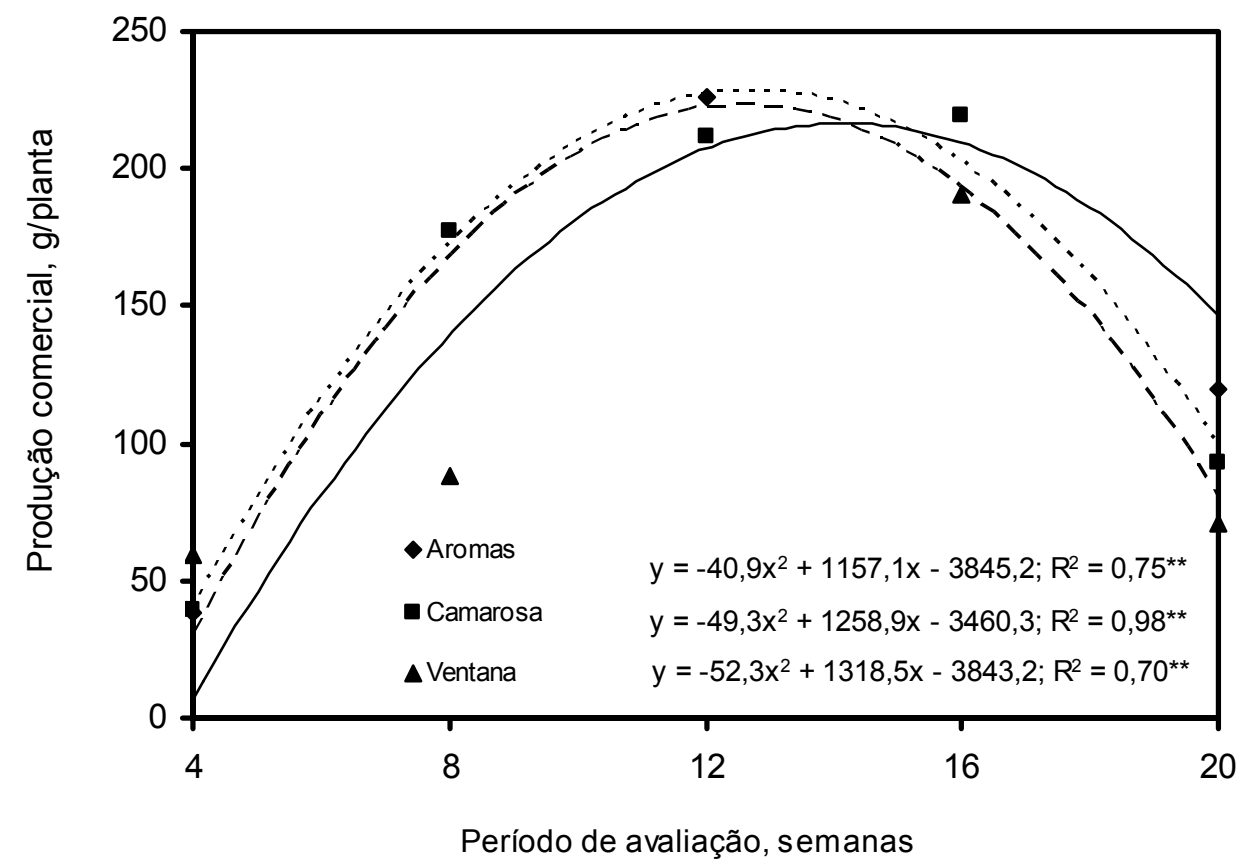

FIGURA 1 - Produtividade média por planta de morangueiro, em função da cultivar e do período de colheita.

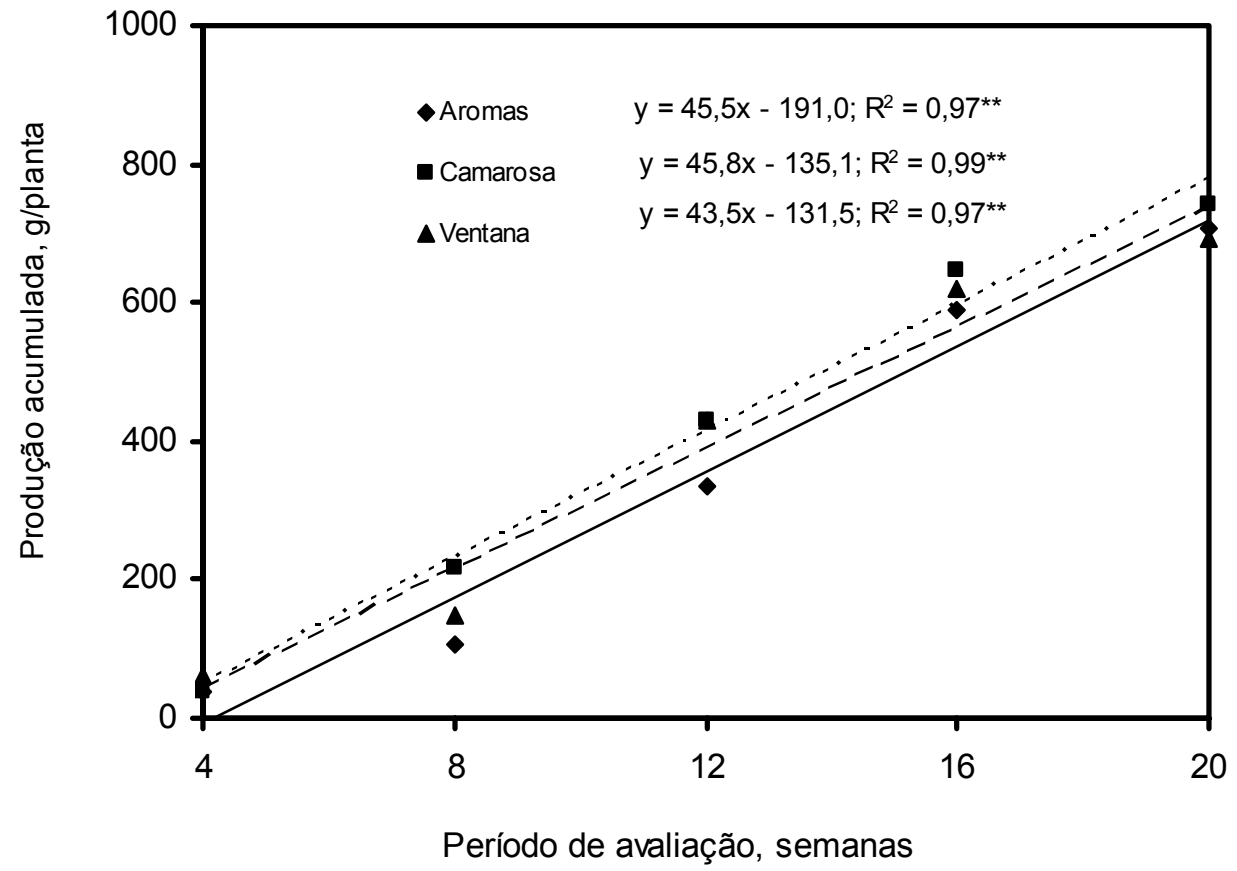

FIGURA 2 - Produtividade acumulada média por planta de morangueiro, em função da cultivar e ao longo do período de colheita. 
OLIVEIRA, R.P.; SCIVITTARO, W.B. Desempenho produtivo de...

TABELA 2 - Produtividade acumulada de fruta comercial de morangueiro em função da cultivar e do período de avaliação.

\begin{tabular}{|c|c|c|c|c|c|}
\hline \multirow[t]{2}{*}{ Cultivar } & \multicolumn{5}{|c|}{ Período de avaliação ${ }^{1}$, semanas } \\
\hline & 1 a 4 & 1 a 8 & 1 a 12 & 1 a 16 & 1 a 20 \\
\hline Aromas & $38,7^{\text {ns }}$ & $107,4 b$ & $333,5 b$ & $588,7^{\mathrm{ns}}$ & $708,7^{\mathrm{ns}}$ \\
\hline Camarosa & 39,7 & $216,8 a$ & $428,1 a$ & 647,0 & 740,2 \\
\hline Ventana & 59,1 & $147,5 a b$ & $430,8 a$ & 621,1 & 691,5 \\
\hline
\end{tabular}

\begin{tabular}{|c|c|}
\hline $\mathrm{CV}($ cultivar $)=8,3 \%$ & $C V($ período de avaliação $)=5,6 \%$ \\
\hline
\end{tabular}

Para todas as três cultivares de morangueiro, produção de frutas de maior tamanho foi obtida entre a $5^{\mathrm{a}}$ e $8^{\mathrm{a}}$ semanas de colheita. Até o terceiro subperíodo de colheita, a cultivar Ventana produziu frutos de maior massa média, sendo que até a oitava semana, a 'Camarosa' apresentou desempenho intermediário e a 'Aromas' produziu as menores frutas. No subperíodo seguinte, as cultivares Aromas e Camarosa não diferiram entre si quanto à massa média de frutas. No quarto subperíodo de colheita (13 a $16^{a}$ semanas), não houve diferença entre as cultivares quanto ao tamanho de frutas. Já entre a $17^{\mathrm{a}}$ e $20^{\mathrm{a}}$ semanas de colheita, houve uma inversão de comportamento em relação aos subperíodos iniciais, com a 'Ventana' produzindo frutos menores que as demais cultivares (Tabela 3). Assim como o tamanho das frutas, que diminuiu especialmente nos dois últimos subperíodos de colheita, também a qualidade das frutas diminuiu à medida que se aproximou do final do período de colheita, coincidindo com o final do ano, em que as temperaturas são maiores. Este é um comportamento comum entre cultivares de morangueiro, conforme reportado por Oliveira et al. (2008).

TABELA 3 - Massa média da fruta de morangueiro em função da cultivar e do período de avaliação.

\begin{tabular}{|c|c|c|c|c|c|}
\hline \multirow[t]{2}{*}{ Cultivar } & \multicolumn{5}{|c|}{ Período de avaliação ${ }^{1}$, semanas } \\
\hline & 1 a 4 & 5 a 8 & 9 a 12 & 13 a 16 & 17 a 20 \\
\hline & & & g fruta ${ }^{-1}$ & 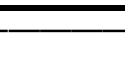 & -------- \\
\hline Aromas & $14,3 \mathrm{c}$ & $21,6 b$ & $18,8 b$ & $12,6 a$ & $9,5 a$ \\
\hline Camarosa & $18,6 b$ & $24,4 a b$ & $17,3 b$ & $13,4 a$ & $9,7 a$ \\
\hline Ventana & $22,5 a$ & $26,8 a$ & $23,0 a$ & $13,1 \mathrm{a}$ & $5,2 b$ \\
\hline
\end{tabular}

CV(cultivar) $=7,1 \%$

$\mathrm{CV}$ (período de avaliação) $=12,5 \%$

${ }^{1}$ Período de avaliação a partir do início da colheita em agosto. Médias seguidas de mesma letra nas colunas não diferem significativamente entre si pelo teste de Tukey $(p<0,05)$.

Ainda na Tabela 3, verifica-se que a massa média da fruta das três cultivares avaliadas, Ventana, Camarosa e Aromas, nas 12 primeiras semanas de produção foi superior ao patamar de comercialização estabelecido para morango tipo extra: $14 \mathrm{~g}$ por fruta (Rebelo \& Balardin, 1997). D'Anna \& Prinzivalli (2002), na Itália, obtiveram massa média semelhante das frutas, sendo, em média, 15,2 $\mathrm{g}$ para a 'Camarosa' e 16,3 g para a 'Aromas'.

A partir dos dados da Figura 3, determinaram-se os valores máximos para massa média da fruta, quais foram: $25,3 \mathrm{~g}$ para a cultivar Ventana, na $8^{a}$ semana de colheita; $18,9 \mathrm{~g}$ para a cultivar Aromas, na $10^{\mathrm{a}}$ semana de colheita, e $20,8 \mathrm{~g}$ para a cultivar Camarosa, na $7^{a}$ semana de colheita (Figura 3). Estes resultados evidenciam o potencial da cultivar Ventana para a produção de frutas de classificação extra quanto ao tamanho, ou seja, com mais de $14 \mathrm{~g}$ segundo Rebelo \& Balardin (1997). 
OLIVEIRA, R.P.; SCIVITTARO, W.B. Desempenho produtivo de...

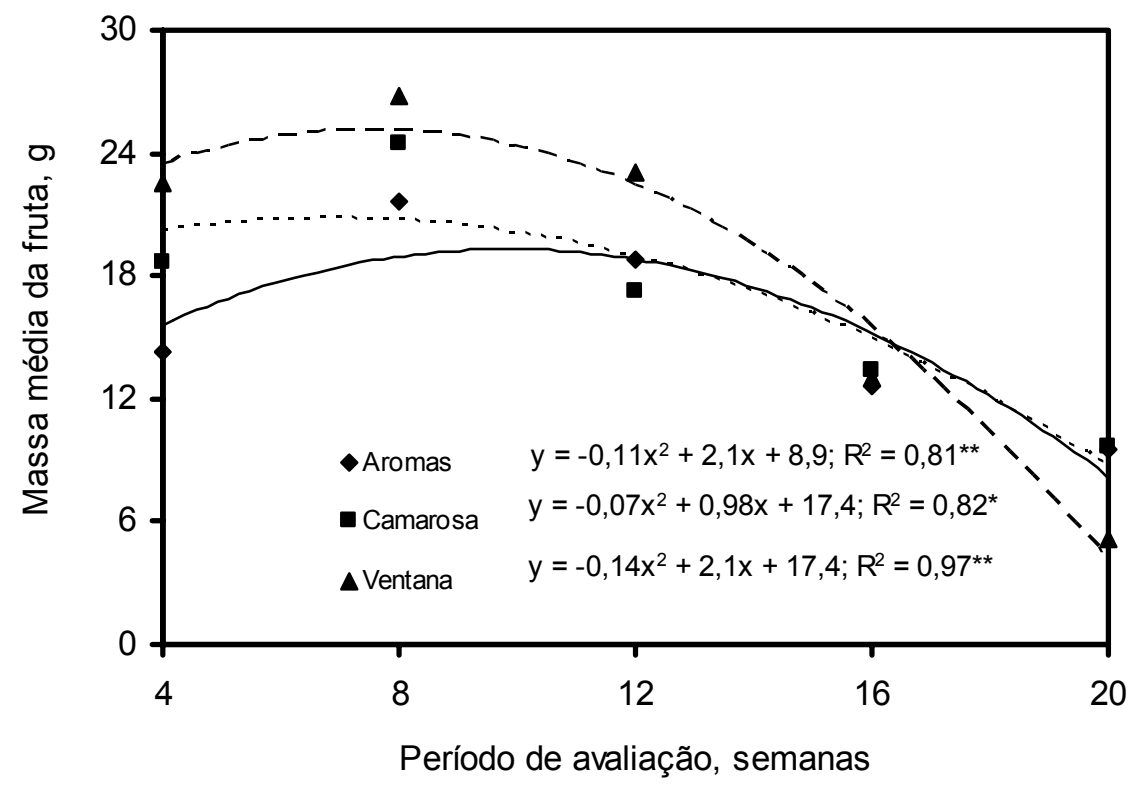

FIGURA 3 - Massa média da fruta fresca de morangueiro, em função da cultivar e do período de colheita.

\section{CONCLUSÕES}

A cultivar de morangueiro Ventana é tão produtiva quanto as cultivares Aromas e Camarosa.

As cultivares Aromas e Camarosa apresentam maior regularidade de produção que a Ventana.

A cultivar Ventana apresenta massa média da fruta elevada, superior a $22 \mathrm{~g}_{2}$ até a décima segunda semana de produção.

\section{AGRADECIMENTOS}

À FAPERGS e ao CNPq pelo apoio financeiro ao projeto.

\section{CONFLITOS DE INTERESSES}

Não foram identificadas situações de conflitos de interesses no presente trabalho.

REFERÊNCIAS

1. AGRIANUAL 2008. Morango. In: Anuário da Agricultura Brasileira (Ed.). 13. ed. São Paulo: FNP Consultoria e Agrolnformativos, 2008. p. 419.

2. CANTILLANO, R.F.F. Seleção e classificação. In: ANTUNES, L.E.C.; DUARTE FILHO, J. (Ed.). Sistema de produção de morango. Disponível em: <http://sistemasdeproducao.cnptia.embrapa.br/FontesHTML/Morango/ SistemaProducaoMorango/cap13.htm>. Acesso em: 30 out. 2005

3. CASTRO, R.L.; CASALI, V.W.D.; BARRELLA, T.P.; SANTOS, R.H.S.; CRUZ, C.D. Comportamento de dez cultivares de morangueiro em cultivo orgânico. Horticultura Brasileira, v. 21, n. 2, p. 227-230, 2003.

4. D'ANNA, F.; PRINZIVALLI, C. Due anni di studio su varietà di fragola per l'ambiente protetto meridionale. Rivista di Frutticoltura e di Ortofloricoltura, v. 64, n. 6, p. 61-68, 2002.

5. DURNER, E.F. et al. Early season yield responses of selected strawberry cultivars to photoperiod and chilling in a Florida winter production system. Journal of the American Society for Horticultural Science, v. 112, n. 1, p. 53-56, 1987.

6. LARSON, K.; SHAW, D. The Ventana strawberry cultivar. Disponível em: <http://fruitsandnuts.ucdavis.edu/ strawberry/Website Ventana Strawberry Cultivar final.pdf>. Acesso em: 05 jan. 2009.

7. LEIS, M. et al. Naiad Civl35. Rivista di Frutticoltura e di Ortofloricoltura, v. 64, n. 6, p. 48-49, 2002.

8. OLIVEIRA, R.P. et al. Mudas certificadas de morangueiro: maior produção e melhor qualidade da fruta. A Lavoura, v. 108, n. 655 , p. $35-38,2005$

9. OLIVEIRA, R.P. et al. Produção de morangueiro da cv. Camino Real em sistema de túnel. Revista Brasileira de Fruticultura, v. 30, n. 3, p. 681-684, 2008

10. REBELO, J.A.; BALARDIN, R.S. A cultura do morangueiro. 3. ed. Florianópolis: EPAGRI, 1997. 44 p. (EPAGRI. Boletim Técnico, 46).

11. RONQUE, E.R.V. Cultura do morangueiro; revisão e prática. Curitiba: Emater, 1998. 206 p.

12. SANTOS, A.M. Cultivares. In: SANTOS, A.M.; MEDEIROS, A.R.M. (Ed.). Morango; produção. Brasília: Embrapa Informação Tecnológica, 2003. p. 24-30. (Embrapa Informação Tecnológica. Frutas do Brasil, 40).

Recebido em 13/01/2010

Aceito em 12/07/2011 